\title{
Impact of changing life style on age of menarche
}

\author{
Kritika Upadhyay ${ }^{1 *}$, Archana Dhok ${ }^{2}$, Arpita Jaiswal ${ }^{3}$
}

${ }^{1}$ Student, ${ }^{2}$ Department of Biochemistry, ${ }^{3}$ Department of Obstetrics and Gynecology, Jawaharlal Nehru Medical College, DMIMS (DU), Sawangi (Meghe), Maharashtra, India

Received: 25 February 2019

Accepted: 09 May 2019

*Correspondence:

Dr. Kritika Upadhyay,

E-mail:kritika0702@gmail.com

Copyright: () the author(s), publisher and licensee Medip Academy. This is an open-access article distributed under the terms of the Creative Commons Attribution Non-Commercial License, which permits unrestricted non-commercial use, distribution, and reproduction in any medium, provided the original work is properly cited.

\section{ABSTRACT}

Background: Menarche marks the beginning of the reproductive phase in a woman's life or the onset of puberty Menarche is said to be early when it begins before the age of 8 years in a girl's life. Early menarche can turn up into many consequences. This can only be controlled by carefully exploring and analyzing the factors causing early menarche. This study aims to assess the impact of changing lifestyle on age of menarche.

Methods: It is a prospective cross-sectional study, included 112 subjects in group I (girls had their menarche at the age of <11 years) and 88 subjects in group II (Girls had their menarche at the age between 12-14 years). A self-made questionnaire was used for collecting the data.

Results: It is found that $80.32 \%$ girls from group I and $47.73 \%$ girls from group II consume junk food daily or $2-3$ times per week. $66.07 \%$ girls from group I and $51.14 \%$ girls from group II play indoor games daily or 2-3 times per week. 52.86\% girls from group I and $26.14 \%$ girls from group II go to hotel once a week and 57.14\% girls from group I and $73.86 \%$ girls from group II go to hotel occasionally.

Conclusions: Girls who are not much interested in playing outdoor games, more frequently go to hotel, eat more junk food and consume more amount of fats in the daily home-made food have a significant lowering in the age of menarche.

Keywords: Early menarche, Lifestyle, Menarche, Reproductive phase

\section{INTRODUCTION}

Menarche indicates the beginning of the reproductive phase in a woman's life or the onset of puberty. Average age of menarche is $12-14$ years. Menarche is said to be early when it begins before the age of 8 years in a girl's life. ${ }^{1}$ A review of studies on mean menarche age of girls from 1960s onwards showed that there is a consistent lowering of age at menarche on an average, by about six months per decade. ${ }^{2}$ The age of menarche is variable. It very much depends on the interaction between the hereditary factors and the environmental factors. The majority of the genetic factors influencing the age of menarche are unknown. According to a cross sectional study performed on a number of Columbian women the age of menarche is affected by the habit of exercising. ${ }^{3}$

Early menarche can turn up into consequences like obesity, cardiovascular abnormalities, increasing risk of breast cancer, endometriosis of the uterus, polycystic ovarian syndrome and cancer of the uterus. ${ }^{4-6}$ This can only be controlled by carefully exploring and analyzing the factors causing early menarche. Dietary habits and physical activity may have some effect on age of 
menarche. As there is paucity of data about the factors which influences the age of menarche, present study will be carried out to find out the role of dietary factors, dietary habits, and physical activity on the age of menarche. The need of this study is to know the factors which influences the age of menarche so that the girls can be prevented from consequences arising due to early menarche and help them to avoid the social and psychological stress and lead a healthy life while serving the country.

\section{METHODS}

It was a prospective cross-sectional study carried out in the Department of Biochemistry, JNMC, Sawangi, (M) Wardha, Maharashtra, India after getting the ethical clearance from the Institutional Ethical Committee (IEC) (IEC Ref No: DMIMS (DU)/IEC/2018-19/7145).

Study subjects included 112 subjects in group I (girls had their menarche at the age of $<11$ years) and 88 subjects in group II (Girls had their menarche at the age between 1214 years).

\section{Procedure}

After taking prior permission from the principals of the respective schools, phone numbers of the parents were taken. Oral consent was obtained from their parents and girls for filling up the required details in the proforma.

Detail history was obtained from their parents regarding height, weight, dietary habits, life style, exercise, indoor and outdoor activities etc. of their children. All the information was obtained as per proforma from the parents for better reliability and validity. The self-made questionnaire which was used for data collection includes the general information of the girl (name, age, standard, address, height, weight etc. It also includes the occupation of parents, her age of menarche and her mother's age of menarche (with any other complaints).The other part of questionnaire includes the daily or occasional habits comprising the dietary habits, exercise, indoor and outdoor activities etc.

\section{RESULTS}

The mean age of the onset of menarche of the girls included in study was 10.5 and 12.9 years in group I and group II respectively (Figure 1).

On comparing the height of girls in both the groups the mean height was 4.54 and 4.79 feet in group I and II respectively which was significant $(\mathrm{p}=0.0001)$ (Table 1$)$. It shows that girls of group I in comparison to girls of group II have less mean height.

On comparing the mean weight in $\mathrm{kg}$ in both the groups the mean weight in group I is 35.27 and in group II it is 36.87. The data is not significant $(\mathrm{p}=0.063)$ (Table 2).

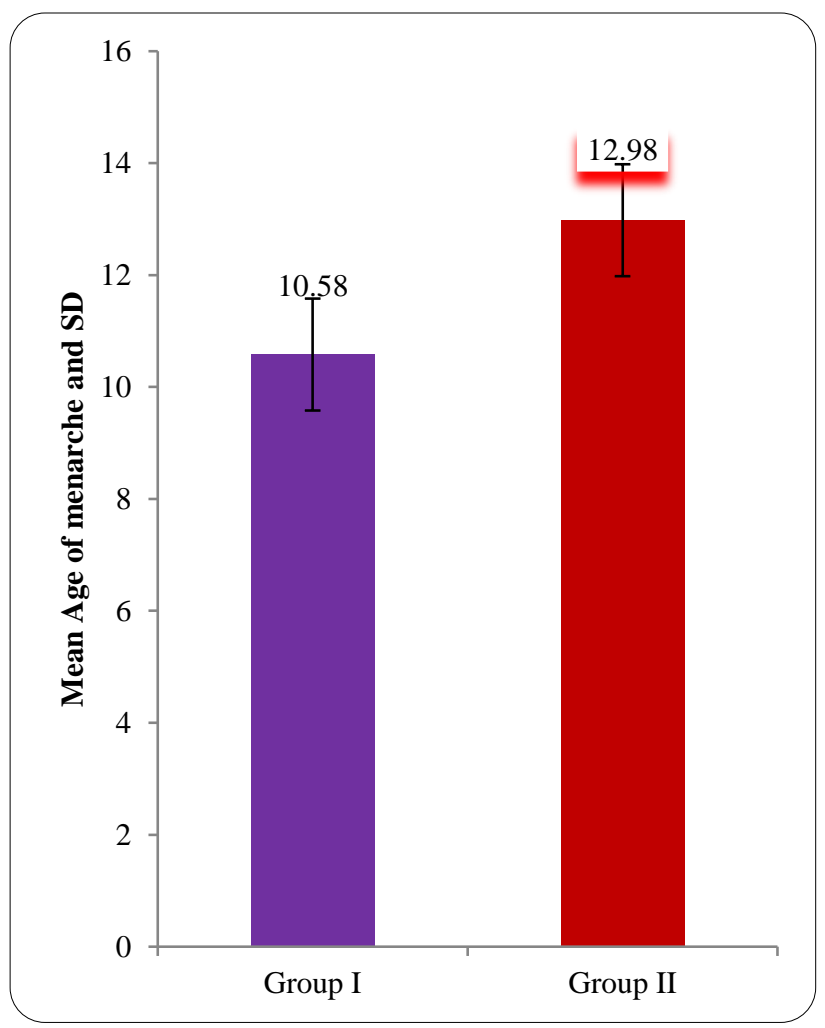

Figure 1: Mean age of menarche in two groups.

Table 1: Comparison height in feet in two groups.

\begin{tabular}{|llllll|}
\hline Group & N & Mean & Std. deviation & Std. error mean & Z value \\
\hline Group I & 112 & 4.54 & 0.35 & 0.033 & 4.84 \\
\hline Group II & 88 & 4.79 & 0.37 & 0.040 & $\mathrm{P}=0.0001,(\mathrm{~S})$ \\
\hline
\end{tabular}

$(\mathrm{HS})=$ Highly Significant, $(\mathrm{S})=$ Significant, $(\mathrm{NS})=$ Not significant (Student's unpaired t test).

Table 2: Comparison of weight (kg) in two groups.

\begin{tabular}{|llllll|}
\hline Group & N & Mean & Std. deviation & Std. error mean & Z value \\
\hline Group I & 112 & 35.27 & 6.69 & 0.63 & 1.87 \\
\cline { 1 - 3 } & 88 & 36.87 & 4.84 & 0.51 & $\mathrm{P}=0.063,(\mathrm{NS})$ \\
\hline
\end{tabular}

$(\mathrm{HS})=$ Highly Significant, $(\mathrm{S})=$ Significant, $(\mathrm{NS})=$ Not significant (Student's unpaired t test). 
Table 3: Comparison of BMI $\left(\mathrm{kg} / \mathrm{m}^{2}\right)$ in two groups.

\begin{tabular}{|llllll|}
\hline Group & N & Mean & Std. deviation & Std. error mean & Z-m \\
\cline { 1 - 4 } & 112 & 18.45 & 3.34 & 0.31 & 1.96 \\
\cline { 1 - 5 } Grou II & 88 & 17.50 & 3.41 & 0.36 & $\mathrm{P}=0.051$, (NS) \\
\hline
\end{tabular}

$(\mathrm{HS})=$ Highly Significant, $(\mathrm{S})=$ Significant, $(\mathrm{NS})=$ Not significant (Student's unpaired t test).

On comparison of BMI in both the groups the mean BMI in group I is 18.45 and in group II it is 17.50 . The data is not significant $(\mathrm{p}=0.051)$ (Table 3$)$.

It is found that $42.86 \%$ girls of group I have a habit of eating junk food daily from outside which is high in contrast to only $22.73 \%$ girls of group II. Also $37.50 \%$ of group I like to have junk food at least 2-3 times in a week which is more in comparison to girls of group II $(25 \%)$. Moreover $32.95 \%$ and $19.32 \%$ of girls from group II like to have junk food either once a week or occasionally respectively. This data is highly significant $(\mathrm{p}=0.0001)$ (Table 4).

It is observed that effect of playing indoor games $66.07 \%$ girls from group I and $51.14 \%$ girls from group II play indoor games daily or 2-3 times per week. Also, 33.93\% girls from group I and $48.86 \%$ girls from group II play indoor games once a week or occasionally. It shows that girls of group I like to play indoor games more often than girls of group II. This data is significant $(\mathrm{p}=0.0018)$ (Table 5).

Table 4: Effect of junk food from outside.

\begin{tabular}{|c|c|c|c|}
\hline Junk food from outside & Group I (N=112) & Group II (N=88) & X2-value \\
\hline Daily & $48(42.86 \%)$ & $20(22.73 \%)$ & \multirow{4}{*}{$\begin{array}{l}23.71 \\
\mathrm{P}=0.0001,(\mathrm{HS})\end{array}$} \\
\hline 2-3 times/ week & $42(37.50 \%)$ & $22(25 \%)$ & \\
\hline Once a week & $14(12.50 \%)$ & $29(32.95 \%)$ & \\
\hline Occasionally & $8(7.14 \%)$ & $17(19.32 \%)$ & \\
\hline
\end{tabular}

(HS)= Highly Significant, (S) = Significant, (NS) = Not significant (Student's unpaired t test).

Table 5: Effect of indoor games.

\begin{tabular}{|c|c|c|c|}
\hline Indoor games & Group I $(\mathrm{N}=112)$ & Group II ( $\mathbf{N = 8 8 )}$ & X2-value \\
\hline Daily & $20(17.86 \%)$ & $12(13.64 \%)$ & \multirow{4}{*}{$\begin{array}{l}15.00 \\
P=0.0018,(S)\end{array}$} \\
\hline 2-3 times/ week & $54(48.21 \%)$ & $33(37.50 \%)$ & \\
\hline Once a week & $18(16.07 \%)$ & $35(39.77 \%)$ & \\
\hline Occasionally & $20(17.86 \%)$ & $8(9.09 \%)$ & \\
\hline
\end{tabular}

$(\mathrm{HS})=$ Highly Significant, $(\mathrm{S})=$ Significant, $(\mathrm{NS})=$ Not significant (Student's unpaired t test).

Table 6: Effect of hotelling.

\begin{tabular}{|c|c|c|c|}
\hline Hotelling & Group I (N=112) & Group II (N=88) & X2-value \\
\hline Daily & $00(0 \%)$ & $00(0 \%)$ & \multirow{4}{*}{$\begin{array}{l}6.01 \\
\mathrm{P}=0.014,(\mathrm{~S})\end{array}$} \\
\hline 2-3 times/ week & $00(0 \%)$ & $00(0 \%)$ & \\
\hline Once a week & $48(42.86 \%)$ & $23(26.14 \%)$ & \\
\hline Occasionally & $64(57.14 \%)$ & $65(73.86 \%)$ & \\
\hline
\end{tabular}

$(\mathrm{HS})=$ Highly Significant, $(\mathrm{S})=$ Significant, $(\mathrm{NS})=$ Not significant (Student's unpaired t test).

Table 7: Effect of Watching TV.

\begin{tabular}{|c|c|c|c|}
\hline Watching TV (Hours) & Group I (N=112) & Group II (N=88) & X2-value \\
\hline 1-2 hrs/day & $52(46.43 \%)$ & $43(48.86 \%)$ & \multirow{4}{*}{$\begin{array}{l}5.89 \\
\mathrm{P}=0.11,(\mathrm{NS})\end{array}$} \\
\hline 2-3 hrs/day & $42(37.50 \%)$ & $40(45.45 \%)$ & \\
\hline 3-4 hrs/day & $14(12.50 \%)$ & $03(3.41 \%)$ & \\
\hline 4-5 hrs/day & $4(3.57 \%)$ & $02(2.27 \%)$ & \\
\hline
\end{tabular}

$(\mathrm{HS})=$ Highly Significant, $(\mathrm{S})=$ Significant, $(\mathrm{NS})=$ Not significant (Student's unpaired t test). 
On comparing the frequency of having food in a hotel $52.86 \%$ girls from group I and $26.14 \%$ girls from group II go to hotel once a week and $57.14 \%$ girls from group I and $73.86 \%$ girls from group II go to hotel occasionally. Number of girls of group I are more frequent in eating food from hotel than number of girls in group II. This data is found to be significant $(\mathrm{p}=0.014)$ (Table 6).

On the other hand effect of watching TV, effect of Intake of butter, cheese, oil, ghee, in homemade recipes, effect of exercise (other than school), effect of outdoor games (park/ground) was not found to be significant (Table 7, Table 8, Table 9 and Table 10).

More number of girls in group I have a habit of watching TV for long hours as compared to number of girls in group II which implies that they are less involved in doing physical activities. $12.50 \%$ of girls of group I have a habit of watching TV 3-4 hrs a day which is more as compared to the girls watching TV for 3-4 hrs in group II $(3.41 \%)$.This data is not significant as per calculations $(\mathrm{p}=0.11)$ (Table 7).

Table 8: Effect of Intake of butter, cheese, oil, ghee, in homemade recipes.

\begin{tabular}{|llll|}
\hline Intake of butter, cheese, oil, ghee, in homemade recipes & Group I $(\mathbf{N}=112)$ & Group II (N=88) & X2-value \\
\hline Daily & $20(17.86 \%)$ & $13(14.77 \%)$ & 5.54 \\
\hline 2-3 times/ week & $60(53.57 \%)$ & $36(40.91 \%)$ & P=0.13, \\
\hline Once a week & $25(22.32 \%)$ & $32(36.36 \%)$ & $(\mathrm{NS})$ \\
\hline Occasionally & $7(6.25 \%)$ & $7(7.95 \%)$ & \\
\hline
\end{tabular}

$($ HS $)=$ Highly Significant, $(\mathrm{S})=$ Significant, $(\mathrm{NS})=$ Not significant (Student's unpaired t test).

Table 9: Effect of exercise (other than school).

\begin{tabular}{|c|c|c|c|}
\hline Exercise (other than school) & Group I (N=112) & Group II ( $\mathbf{N = 8 8 )}$ & X2-value \\
\hline Daily & $20(17.86 \%)$ & $25(28.41 \%)$ & \multirow{4}{*}{$\begin{array}{l}7.09 \\
\mathrm{P}=0.13,(\mathrm{NS})\end{array}$} \\
\hline 2-3 times/ week & $17(15.18 \%)$ & $20(22.73 \%)$ & \\
\hline Once a week & $20(17.86 \%)$ & $10(11.36 \%)$ & \\
\hline Occasionally & $23(20.54 \%)$ & $12(13.64 \%)$ & \\
\hline Never & $32(28.57 \%)$ & $21(23.86 \%)$ & \\
\hline
\end{tabular}

$(\mathrm{HS})=$ Highly Significant, $(\mathrm{S})=$ Significant, $(\mathrm{NS})=$ Not significant (Student's unpaired t test).

Table 10: Effect of outdoor games (park/ground).

\begin{tabular}{|c|c|c|c|}
\hline Outdoor games (park/ground) & Group I (N=112) & Group II ( $\mathrm{N}=\mathbf{8 8})$ & X2-value \\
\hline Daily & $38(33.93 \%)$ & $32(36.36 \%)$ & \multirow{4}{*}{$\begin{array}{l}4.05 \\
\mathrm{P}=0.25,(\mathrm{NS})\end{array}$} \\
\hline 2-3 times/ week & $20(17.86 \%)$ & $24(27.27 \%)$ & \\
\hline Once a week & $24(21.43 \%)$ & $12(13.64 \%)$ & \\
\hline Occasionally & $30(26.79 \%)$ & $20(22.73 \%)$ & \\
\hline
\end{tabular}

$(\mathrm{HS})=$ Highly Significant, (S) = Significant, (NS) = Not significant (Student's unpaired t test).

\section{DISCUSSION}

Data from the present study shows an earlier onset of menarche in the girls who are not physically active that is do not play outdoor games much and do not exercise regularly, more frequently go to restaurants, eat more junk food and consume more oily and cheesy foods.

Gaudineau et al, stated that early-maturing girls may affiliate with older adolescents, hence engage in risk behaviors linked to their appearance rather than their maturity level. ${ }^{7}$

A study conducted in 2013 by Vani K et al, showed that Lifestyle modifications like regular physical activity, decreasing the intake of junk food and promoting healthy eating habits will help improve the menstrual health among girls. ${ }^{8}$

According to a recent longitudinal study (Mueller NT et al) published in the American Journal of Clinical Nutrition, consumption of caffeinated and artificially sweetened soft drinks was positively associated with risk of early menarche. ${ }^{9}$ Recently, the study (Pitynski D et al) published in Medical Hypotheses stating that a high salt diet can result in an earlier onset of puberty. ${ }^{10}$

As concluded in a study by Shinde $\mathrm{P}$ et al, by correcting the food habits and lifestyle there will be definite reduction in menstrual disorders. ${ }^{11}$ The feeding habit and physical activities directly affecting the menstrual health of adolescent girls as suggested by Negi $\mathrm{P}$ et al, in $2018 .^{12}$ 
The levels of the hormones insulin, leptin and estrogen are altered by the level of fats in our body which in turn are responsible for early puberty. Decrease in physical activity can decrease the level of melatonin hormone which does the same effect. Increased intake of total protein, animal protein, and meat in young children can cause early menarche in girls. ${ }^{13}$

\section{Implications}

Early menarche leads to increased risk of obesity, cardiovascular diseases; cancers specially breast cancer, diabetes mellitus and metabolic syndrome, altered psychosocial behavior, abnormal sexual behavior, anxiety, depression and other health problems.

To avoid these problems studies are needed to find out the adverse effect of changing lifestyle on age of menarche so that future generation can be benefited by counseling them for change in lifestyle and developing healthy hygiene, food and exercise habits. There can be a lot of other factors which may have a influence on the age of menarche which are yet to be discovered. Therefore we are been in a need of lots of studies and research.

\section{ACKNOWLEDGMENTS}

Authors would like to thank all the girls and their guardians for participating in this study, the guide and the head of the institution for granting permission to conduct this study.

\section{Funding: No funding sources}

Conflict of interest: None declared

Ethical approval: The study was approved by the Institutional Ethics Committee (IEC Ref No: DMIMS (DU)/IEC/2018-19/7145)

\section{REFERENCES}

1. Posner RB. Early menarche: a review of research on trends in timing, racial differences, etiology and psychosocial consequences. Sex Roles. 2006;54:315.

2. Bagga A, Kulkarni S. Age at menarche and secular trend in Maharashtrian (Indian) girls. Acta Biol Szegediensis. 2000;44(1-4):53-7.

3. Karapanou O, Papadimitriou A. Determinants of menarche. Repro Biol Endocrinol. 2010;8:115.
4. Canoy D, Beral V, Balkwill A, Wright FL, Kroll ME, Reeves GK, et al. Age at menarche and risks of coronary heart and other vascular diseases in a large UK cohort. The million women study. 2015;131:23744.

5. Hsieh CC, Trichopoulos D, Katsouyanni K, Yuasa S. Age at menarche, age at menopause, height and obesity as risk factors for breast cancer: associations and interactions in an international case-control study. Int J Cancer. 1990;46:796-800.

6. Nnoaham KE, Webster P, Kumbang J, Kennedy SH, Zondervan $\mathrm{K}$. Is early age at menarche a risk factor for endometriosis? A systematic review and metaanalysis of case-control studies. Fertil Steril. 2012;98(3):702-12.e6.

7. Gaudineau A, Ehlinger V, Vayssiere C, Journet B, Arnaud C, Godeau E. Factors associated with early menarche: results from the French Health Behaviour in School-aged Children (HBSC) study. BMC Pub Heal. 2010;10:175.

8. Vani RK, Veena KS, Subitha L, Kumar VR, Bupathy A. Menstrual abnormalities in school going girls-are they related to dietary and exercise pattern? J Clin Diagno Res. 2013;7(11):2537-40.

9. Mueller NT, Jacobs DR, MacLehose RF, Demerath EW, Kelly SP, Dreyfus JG, et al. Consumption of caffeinated and artificially sweetened soft drinks is associated with risk of early menarche. Am J Clin Nutr. 2015;102(3):648-54.

10. Pitynski D, Flynn FW, Skinner DC. Does salt have a permissive role in the induction of puberty? Med Hypothes. 2015;85(4):463-7.

11. Shinde P, Vyas K, Goel S, Sharma OR. Effects of junk food / fast food on menstrual health: a review study. Int Ayurved Med J. 2017;2(1):867-71.

12. Negi P, Mishra A, Lakhera P. Menstrual abnormalities and their association with lifestyle pattern in adolescent girls of Garhwal, India. J Family Med Primary Care. 2018;7(4):804-8.

13. Huffpost. The blog: Girl's early puberty: what causes it, and how to avoid it, 2011. Available at: https://m.huffpost.com/us/entry/857167.

Cite this article as: Upadhyay K, Dhok A, Jaiswal A. Impact of changing life style on age of menarche. Int J Reprod Contracept Obstet Gynecol 2019;8:2261-5. 